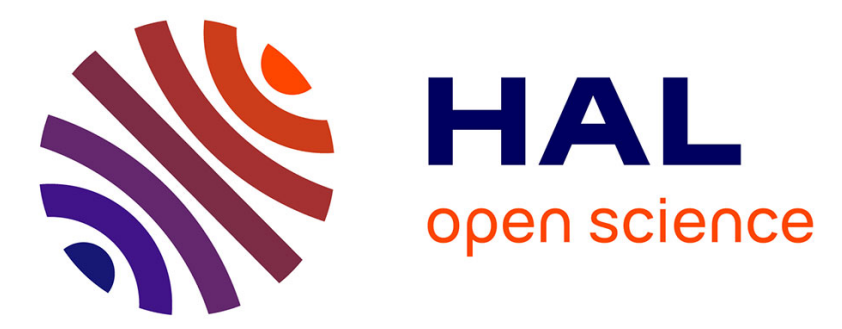

\title{
BIOENERGETICAL AND CARDIAC ADAPTATIONS OF PILOTS TO A 24-HOUR TEAM KART RACE
}

Sylvain Durand, Michael Ripamonti, Abderrahmane Rahmani, Bruno Beaune

\section{To cite this version:}

Sylvain Durand, Michael Ripamonti, Abderrahmane Rahmani, Bruno Beaune. BIOENERGETICAL AND CARDIAC ADAPTATIONS OF PILOTS TO A 24-HOUR TEAM KART RACE. Journal of Strength and Conditioning Research, 2015, 29 (11), pp.3234 - 3239. 10.1519/JSC.0000000000000630 . hal-02510447

\section{HAL Id: hal-02510447 \\ https://hal.science/hal-02510447}

Submitted on 17 Mar 2020

HAL is a multi-disciplinary open access archive for the deposit and dissemination of scientific research documents, whether they are published or not. The documents may come from teaching and research institutions in France or abroad, or from public or private research centers.
L'archive ouverte pluridisciplinaire HAL, est destinée au dépôt et à la diffusion de documents scientifiques de niveau recherche, publiés ou non, émanant des établissements d'enseignement et de recherche français ou étrangers, des laboratoires publics ou privés. 


\title{
Bioenergetical and Cardiac Adaptations of Pilots to a 24-Hour Team Kart Race
}

\author{
Sylvain Durand, Michael Ripamonti, Abderrahmane Rahmani, and Bruno Beaune \\ Motricité, Interaction, Performance Laboratory, LUNAM University, University of Maine - Le Mans, France
}

ABSTRACT

Durand, S, Ripamonti, M, Rahmani, A, and Beaune, B. Bioenergetical and cardiac adaptations of pilots to a 24-hour team kart race. J Strength Cond Res 29(11): 3234-3239, 2015-This study aimed to evaluate energy expenditure (EE) and heart rate $(\mathrm{HR})$ response in kart pilots to successive driving bouts during a 24-hour team race. Eight adult male pilots (22.8 64.1 years) participated to a team 24-hour speedway kart race in Le Mans (France). They alternatively piloted a 390 $\mathrm{cm}^{3}$ kart. Each relay was 45 minutes long and each pilot performed 4 relays. For each pilot, mean speeds were calculated from lap-to-lap duration recordings using a telemetric infrared timing device. Heart rate values were recorded continuously on 5 -second intervals using a portable cardiometric device. Total energy expenditure (EET) and physical activity ratio (PAR) were determined by accelerometry. To pilot a kart during 45 minutes at a mean speed around $62 \mathrm{~km} \$ \mathrm{~h}^{21}$ induces a $300-\mathrm{kcal} E E T$, corresponding to a 5.6-Mets PAR. This effort is responsive for a $73 \mathrm{~b} \$ \mathrm{~min}^{21}$ increase in HR, from 84.167 .6 to 157.4611 .0 $\mathrm{b} \$ \mathrm{~min}^{21}$ (82\% maximal heart rate intensity). However, during this relay period, HR values seemed independent to mean speed performance and bioenergetical values. Thus, in the context of the 24-hour team race, the variability in effort made during each relay and relay succession did not alter bioenergetical adaptation of pilots to kart driving. The high EE and HR values would be better explained by both emotional stress and environmental constraints such as speedway configuration and vibrations. The way how these factors specifically influence bioenergetical demand, and their relative importance, has to be specified to optimize training procedure and recommendations.

$\mathrm{K}_{\mathrm{EY}} \mathrm{W}_{\mathrm{ORDS}}$ heart rate, energy expenditure, motorsports, exercise
INTRODUCTION

I n motor sports, the sum of mechanical (acceleration or braking forces, gearing, vibrations _ ) and ambient conditions (temperature, helmet, and fire-jacket wearing - ) allow for progressive fatigue development during driving $(2,11,15,20)$. However, because of security rules and phys- ical constraints (i.e., exiguity of the cockpit, discomfort of the apparatuses), measurements remain hard to perform, and few is known about biological adaptations of pilot during training sessions or competitions. In young open-wheel racecar pilots, we recently reported that when driving during 28 minutes at speed values neighboring $130 \mathrm{~km} \$ \mathrm{~h}^{21}$ on speedway, physical activity ratio (PAR) ranged 4.9-5.4 Mets (1 Mets = 1.260 .4 $\mathrm{kcal} \$ \mathrm{~min}^{21}$ mean basal metabolic rate), corresponding to a $177.7621 .9 \mathrm{kcal} \$ \mathrm{~min}^{21}$ mean energy expenditure (EE) (5). Under such conditions, mean heart rate (HR) was around 133 $\mathrm{b} \$ \min ^{21}\left(68_{0}\right.$ maximal heart rate $\left[\mathrm{HR}_{\max }\right]$ intensity) and $\mathrm{HR}$ variations were independent of EE variations (4).

Kart driving is considered to offer similar "speed and racing" sensations than speedway car driving, with similar HR values reaching upper than $150 \mathrm{~b} \$ \mathrm{~min}^{21}(4,22)$ but generally associated to elevated risks of accident and trauma when fatigue occurs (8). It offers to applicants a low-cost opportunity to engage in motorsports and several famous F1 pilots, like Ayrton Senna, Mickael Schumacher, and Lewis Hamilton, were initiated through kart practice, making this activity a growing field of interest. However, little is known about bioenergetical needs for effort management and fatigue development during this activity. Because of the short speedway length and pilot position in the vehicle, kart driv- ing represents a useful tool for scientists to assess physiolog- ical adaptations to driving in "ecological" conditions (22).

Thus, this study aimed (a) to estimate the bioenergetical and physiological demands and (b) to evaluate the effects of repeated bouts of driving on the bioenergetical adaptations and cardiac responses of the pilots during a 24-hour team kart driving competition.

\section{METHODS}

Experimental Approach to the Problem

Observance of the specific rules of karting activity and the respect of physical/mental pilot environment are of main importance to preserve performance release during competition but make measurements hard to perform when 


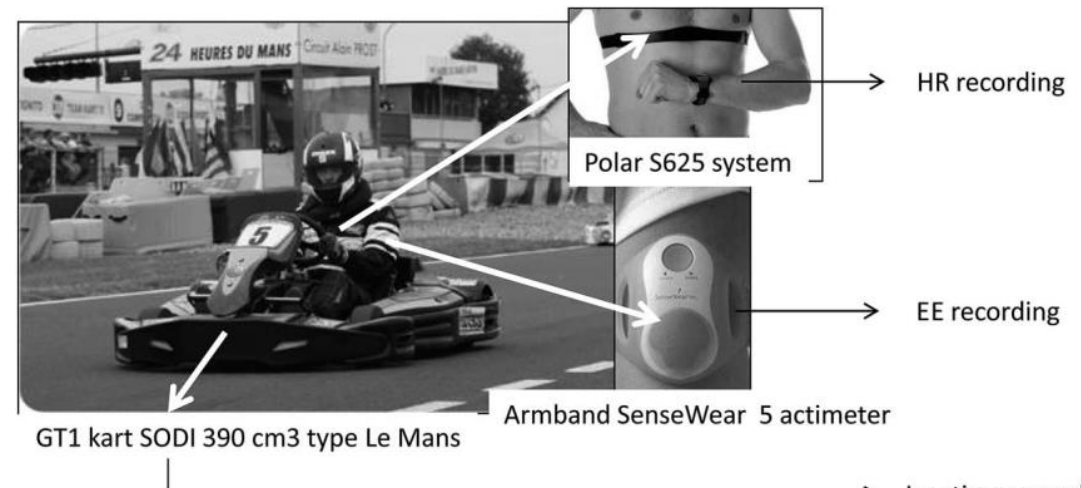

Lap time recording

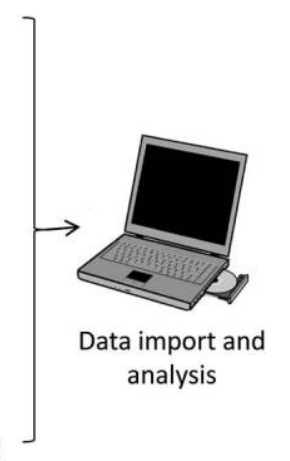

Figure 1. Schematic representation of data testing during race kart driving. $E E=$ energy expenditure; $H R=$ heart rate.

possible. Thus, to obtain pertinent recordings in ecological conditions, our experimental procedure had to avoid any disturbance in team organization, staff management, and pilot habits. As shown previously, the use of small noninvasive sensors such as HR monitors and actimeters allows for reliable bioenergetical and physiological measurements on pilots during a training session without eliciting any discomfort or performance decrease $(4,5)$. During the prerace period, in the aim of reaching rapid stabilization of the parameters, of giving the pilots time to adapt to the presence of sensors and to obtain good quality of data recording, the apparatuses were settled (Figure 1) at least 2 hours before the beginning of the first relay of the first pilot of the team.

During the intermediate phases before or between 2 successive relays, each pilot could freely access to food and drinks provided by team staff. He managed himself his own sleeping and awakening periods but had to stay in or near of the stand. He was leaved free of any experimental constraints but had to respect some recommendations. First, according to team staff, he has to stay quite near of the stand and avoid performing any high-intensity activities such as running,

cycling, or carrying heavy charges, which might induce measurement disturbance during the driving period. Second, good working of the sensors was controlled regularly by direct observation of the displayed data on the watch dial of the HR monitor and of actimeter led lights functioning.

\section{Subjects}

Eight amateur adult pilot students (age, 22.864 .1 years; age rage 18-24 years; body weight, $74.0612 .8 \mathrm{~kg}$; height, 176.96 $6.6 \mathrm{~cm}$ ) voluntarily participated to the experiment after they signed individual informed consent statement, according to national rules and ethical procedures. No particular musculoskeletal disorders, physical impairments, metabolic, or neurological disorders that might affect physiological adaptation to effort were reported.

All pilot students presented at least a 1-year experience for piloting kart on speedway when recruited. They wore specific protection suit, gloves, shoes, crash helmet, and Hans system for neck protection during driving bouts. Between driving bouts, they removed their gloves and crash helmets, opened their suit, and turned it down at hip level to avoid nondriving heat accumulation and discomfort.

\section{Procedures}

Measurements were performed during a 24-hour team race on the "circuit Alain Prost" of Le Mans (lap distance: 1.174 km).

$T_{A B L E}$ 1. Driving performances of kart pilots during the successive relays of the race.

\begin{tabular}{lcccccr}
\hline Driving bout & Relay 1 & Relay 2 & Relay 3 & Relay 4 & Mean & Total \\
\hline Distance covered $(\mathrm{km})$ & 45.261 .1 & 47.061 .4 & 46.562 .0 & 46.162 .4 & 46.262 .1 & 1258 \\
Duration $(\mathrm{min})$ & 44.962 .0 & 45.361 .6 & 45.961 .8 & 44.462 .3 & 45.062 .0 & \\
Mean speed $\left(\mathrm{km} \$ \mathrm{~h}^{21}\right)$ & 60.261 .7 & 62.562 .7 & 60.765 .6 & 62.565 .6 & 61.662 .6 \\
\hline
\end{tabular}

All results are expressed as mean $6 S D$. 
$T_{A B L E}$ 2. Cardiac chronotropic variations and energy expenditure of kart pilots during the successive relays of the race.

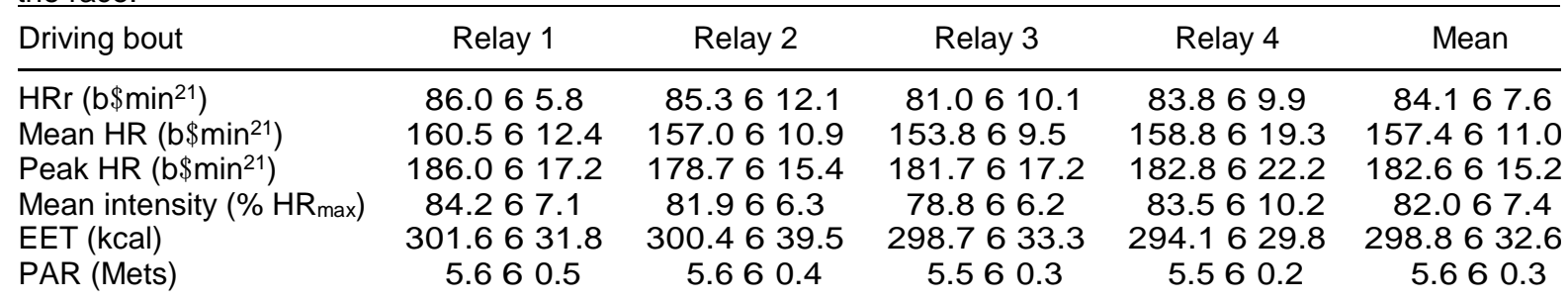

$\mathrm{HR}=$ heart rate; $\mathrm{HR}_{\max }=$ maximal heart rate: $2082(0.73 \mathrm{age})\left(\mathrm{b} \$ \mathrm{~min}^{21}\right)(9) ; \mathrm{HRr}=$ resting $\mathrm{HR} ; \mathrm{EET}=$ total energy expenditure; PAR = physical activity ratio

All results are expressed as mean $6 S D$.

The race started at 1 PM on the Saturday and ended at 1 PM on the Sunday. Every 45 minutes, the 8 pilots alternatively relayed and each pilot performed 4 relays on GT1 kart SODI $390 \mathrm{~cm}^{3}$ type Le Mans. Ambient temperatures ranged from $108 \mathrm{C}$ at $6: 00 \mathrm{AM}$ to $218 \mathrm{C}$ at 5:00 $\mathrm{PM}$.

Sensor position on pilot and data recording are summarized in Figure 1. Lap time was measured continuously using an infrared timing device installed in the kart, and data were used for calculation of mean driving bout speed and driving bout duration. Relay period was imposed for all the participants and precise time of the relay between 2 successive pilots of each team was controlled manually in the stand by the race organization. Heart rate was recorded continuously on 5-second intervals using Polar S625 system (Polar Electro, Kempele, Finland) from 9 AM to 5 PM. Data were transferred to computer through Polar Infrared device and analyzed using the Polar Precision Performance 5.20 software (Polar Electro, Kempele, Finland). Resting periods and driving bouts were characterized after data transfer, identification of the different phases (predriving and rest, driving, interdriving), and extraction on Microsoft Excel Software (4). Resting HR (HRr) was measured at the beginning of the recording period and before each driving bouts. Subjects were quietly seated for 10 minutes in the stand and $\mathrm{HRr}$ correspond to the lowest mean value observed during 1 minute. Mean HR values werecalculated by meaning steady-state values corresponding to each driving bout. Theoretical $\mathrm{HR}_{\max }$ was calculated using the formula developed by Tanaka et al. (18) and mean driving bout intensity was expressed as $\mathrm{HR}_{\max }$ percent $\left.0 \% \mathrm{HR}_{\max }\right)$. Energy expenditure (in kilocalories) was recorded continuously using Armband SenseWear SW5 actimeter (Bodymedia, Pittsburgh, PA) located at the thirst upper right arm part. Total EE (EET, in kilocalories) of each relay and energy cost of kart driving (estimated through PAR, Mets]) were obtained using SenseWear Pro 6.1 software (Bodymedia). The sensor was installed at least 2 hours before the first driving bout of the first pilot and retired half an hour after the last driving bout of the last pilot of the team.

\section{Statistical Analyses}

Values are presented as mean $6 S D$. All tests and analysis were conducted using STATVIEW 5.1 software (Statistical Analysis System, USA). Whatever the data considered, differences between values recorded at each driving bouts were compared using a Wilcoxon's W test procedure and statistical significance was set at $p \# 0.05$.

RESULTS

Each pilot performed 4 relays (range, 44.462 .3 to 45.96 1.8 minutes long), at a $61.662 .6 \mathrm{~km} \$ \mathrm{~h}^{21}$ mean speed (range, 60.261 .7 to $62.565 .6 \mathrm{~km} \mathrm{~h}^{21}$ ) (Table 1). Differences in relay duration or in maximal and mean speed were not significant.

Because of technical interferences or vibrations FC was fully recorded all along the experiment in 6 subjects, but partially recorded ( 3 relays) in 2 pilots. Total EE measure- ments have been achieved in 7 pilots (Table 2). However, because of the low number of subjects and because partial recordings were close to those of the other pilots, all data have been maintained and taken into account.

No significant differences in HR values or in EE values were found when the different relays were compared. HRr, mean HR, and peak HR ranged from 81.0610 .1 to 86.06 $5.8 \mathrm{~b} \$ \mathrm{~min}^{21}$, from 153.869 .5 to $160.5612 .4 \mathrm{~b} \$ \mathrm{~min}^{21}$, and from 178.7615 .4 to $186.0617 .2 \mathrm{~b} \$ \mathrm{~min}^{21}$, respectively. Total energy expenditure and PAR ranged from 301.66 31.8 to $294.1629 .8 \mathrm{kcal}$, and from 5.5060 .28 to 5.616 0.53 Mets, respectively.

\section{Discussion}

Results suggest that like in other motor sports, EE and HR variations are partly independent during kart driving competition. Moreover, driving a $390-\mathrm{cm}^{3} \mathrm{kart}$ on speedway at a $62-\mathrm{km} \$ \mathrm{~h}^{21}$ mean speed during 45 minutes results in a 300 kcal EET, corresponding to a 5.6-Mets PAR. This effort is responsive for a 73-b $\$ \mathrm{~min}^{21}$ increase in $\mathrm{HR}$, reaching $82 \%$ $\mathrm{HR}_{\max }$ intensity $\left(157 \mathrm{~b} \$ \mathrm{~min}^{21}\right)$. 
Physical activity ratio values were closed to those obtained in pilots when driving Formula academy car (5) reflecting a high bioenergetical needs, similar to car driving, motocross riding, and other motorsports $(10,11)$. In these sports, a high interrelationship level is needed between the pilot and the machine to reach a high-performance level. Pilots have to stay seated in the same relatively uncomfortable position with arms slightly bended and their hands strongly gripping the steerwheel. They also have to counteract movements of the (head + helmet) complex due to G-forces when gearing and cornering by activating neck muscles and to maintain vehicle trajectories by activating arm muscles. Such an effort requires high isometric muscle involvement and was proposed as the main explanation for the high PAR values observed $(3,6,10)$. During the same time, pilots push on the breaking or accelerating pedals by activating foot extensor muscles and leg muscles eccentrically. So, we estimated that according to speedway configuration, a kart pilot has exerted over 10-12 braking/acceleration actions on pedals per lap and around 30 laps during a relay. Thus, these muscle activations and works resulted in repeated efforts, as reflected by $\mathrm{V}_{2}$ consumption values obtained from pilots when performing laboratory competition-like tests on road (38.5 $\left.\mathrm{ml} \$ \mathrm{~min}^{21} \$ \mathrm{~kg}^{21}\right)$ or on speedway (21.9 $\mathrm{ml} \$ \mathrm{~min}^{21} \$ \mathrm{~kg}^{21}$ ) (10).

High HR values when driving a car either on city road (140$150 \mathrm{~b} \$ \mathrm{~min}^{21}$ ) or when piloting on speedway were first reported by Taggart and Gibbons (17) (190-205 b $\left.\$ \mathrm{~min}^{21}\right)$. Similar findings were thereafter obtained in professional road drivers or speedway pilots $(10,11)$, student speedway pilots (5),

or motocross riders (11) with HR values ranging 78-98 \% $\mathrm{HR}_{\max }$. The $157 \mathrm{~b} \$ \mathrm{~min}^{21}$ mean HR values we reported when karting are similar to those from Yamakoshi et al. (22) (150 $\mathrm{b} \$ \mathrm{~min}^{21}$ ) but lower than those from Matsumura et al. (12) $\left(171 \mathrm{~b} \$ \mathrm{~min}^{21}\right)$. The reasons of such a discrepancy between HR values in these studies remain unclear but a role for differences in either speedway characteristics or kart power can be hypothesized. However, in these studies kart type but notkart power was indicated, and this hypothesis cannot be verified. Moreover, when comparing HR data measured during repeated driving bouts, a similar evolution can be observed between studies. In Formula academy, a tendency for a slight but regular decrease in mean HR from 143 to $129 \mathrm{~b} \$ \mathrm{~min}^{21}$ occurred between the 3 first 45 minute-driving bouts in student pilots (4). Similarly, when pilots realized 2 successive runs of a kart race mean HR decreases from 169.766 .0 to 166.06 $7.1 \mathrm{~b} \$ \min ^{21}(12)$. These results are in accordance with our findings presented in Table 2, showing that mean HR slightly decreases between relays 1,2 , and 3 from 160.5612 .4 to 157.0610 .9 and $153.869 .5 \mathrm{~b} \$ \mathrm{~min}^{21}$, respectively.

Driving requires the involvement of various muscular parameters but also nervous efficiency. A pilot needs to focus on the trajectory of his vehicle to get the best trajectory and on the movement of the other vehicles to avoid any accident or to prepare a specific maneuver. This "attentional cost" is additional to the physical stress affecting the pilot's body on the circuit and may be responsive for mental fatigue and may enhance risks of accident $(8,13,22)$. However, because during our experiment, neither HR nor mean speed and PAR were significantly modified between driving bouts, and because no significant correlation was found between data variations whatever the driving bout consid- ered (Table 2 ), we cannot point out any apparent proof of fatigue development.

Thus, taken all together, these results indicate that during a 45-minute long kart driving session, isometric and eccen- tric muscular work is not responsive for physical fatigue expression and for affecting HR adaptation to driving. Moreover, the HR decrease between successive driving bouts confirms that the high HR values in motor sports than in other sports with similar EE can be attributed mainly to emotional stress.

Surprisingly, EE and HR values during kart driving (Table 2) were higher than those during Formula academy driving $(4,5)$ while power of the vehicles and mean speed of the relays (Table 1) were lower. This suggests that other factors may influence EE and HR during driving, and by extension fatigue development, additionally to emotional stress. These factors can be grouped in 3 categories: mental stressors (competition vs. training or leisure; experience in driving), driving conditions (vehicle types, speedway characteristics, environmental temper- ature), and physical perturbations (G-forces and vibrations).

It has been shown that driving-dependent stress includes several components and is amplified in condition of competition leading for example to heightened HR during kart driving. For example, it was reported HR values around 170 $\mathrm{b} \$ \min ^{21}$ when measured during races and $\mathrm{HR}$ values around $140 \mathrm{~b} \$ \mathrm{~min}^{21}$ when measured during solo training (12). Similarly, HR values measured when performing successive relays of a 24-hour kart race are similar to those when performing kart driving against the clock $\left(150 \mathrm{~b} \$ \mathrm{~min}^{21}\right)$ (22). Our pilot volunteers were young adults (age: 22.864 .1 years) and 5 of them exhibited 1 year of race kart driving experience only. When comparing 5 experienced F1, GP2, or F3 drivers with 9 junior drivers engaged in Formula Master, equal performance to physical tests but better responses in anticipation and mental parameters were reported in expert drivers than in beginners (14). Thus, it was proposed that faster reaction times in experienced racing drivers than in age-matched physically controls or low-experienced volunteers reflected development of sport-specific adaptations to motor racing requirements that attenuated mental stress $(3,19)$.

During endurance driving or F1 driving, pilots have to adapt to thermal microenvironment sometimes reaching 508 $\mathrm{C}$ in the cockpit due to heat production by the motor (7). This thermal environment may be responsive for homeo- static disturbance resulting in early fatigue (21). In kart driv- ing, the lack of cockpit and pilot position seated before the motor do not favor heat accumulation and cannot be a major factor for EE and HR enhancement. Conversely, evidence exists indicating that $\mathrm{EE}$ and $\mathrm{HR}$ are greater when driving 
Formula 1, than during motocross $(11)$, rally car $(2,10)$, or Formula academy open-wheel car $(4,5)$ in relation to vehicle power. The higher vehicle power is, and by extension maximal speed reached, the higher bioenergetical and functional needs are. However, when considering continuous HR evolution during Formula 1 race simulation on Fiorano speed- way or during Endurance Prototype driving on Le Mans circuit, the greatest $\mathrm{HR}$ values were recorded when and after

cornering (180-195 $\left.\mathrm{b} \$ \mathrm{~min}^{21}\right)$ but not during the faster straight lines (135-145 b $\left.\$ \mathrm{~min}^{21}\right)$ (21). Thus, the relationship between peak speed reached and HR during driving remains ambiguous. During this experiment, EE and HR data recording was totally completed in 6 pilots only and partially in 2 other ones. This did not allow powerful correlation analysis between the main parameters recorded. However, previous measurement on Formula Academy racecars did not point out any significant correlations between these different parameters (4). According to that, it can be proposed that HR and EE responses may reflect rather muscular and mental stress, the pilot was submitted to in response to circuit con-figuration than vehicle differences or speed performance. Indeed, gearing and cornering resulted in amplifying EE to counteract G-forces to maintain the head of the pilot and the vehicle on the optimal trajectory and to avoid risk of crash. Kart driving is generally performed on specific short-length speedway $(1-1.5 \mathrm{~km})$ including 10-15 sharp bends. Each time the pilot has to change his direction, he was submitted to around $600 \mathrm{mG}$ acceleration forces $(12,22)$. At the end of a 30- to 45-minute driving bout, representing over 25-30 laps of speedway, a cumulative EE and HR enhancement may be developed in response to repetition of G-forces application on pilot body: more winding the speedway, more strenuous piloting is. Openwheel cars such as Formula Academy per-form on long-length speedway (longer than $4.5 \mathrm{~km}$ ) and rally cars or endurance prototypes on road circuit. If higher peak speeds in straight lines and G-forces in bends are reached, the delay between 2 successive bends is lower than in kart driving. Thus, it can be considered that, when compared with almost other motor sports, kart drivers could be sub- mitted to a fast accumulation of g-force actions due to circuit configuration, which can be responsive to early fatigue development and trauma (8).

Vibrations caused by rigid suspension systems are responsive for vertical loading in the spine in the vertebral bodies and intervertebral discs and for high working of spinal muscles to maintain posture and minimize vertical stretch and compression (21). Similarly, whole-body vibration, when used as a training method to produce physiological and neuromuscular response, induces HR increase according to vibration frequency (9). A significant increase in $\mathrm{VO}_{2}$ consumption but not HR was also pointed out when comparing cycle riding with high-frequency vibrations, and these effects were attributed to micro-contractions of limb muscles caused by an enhancement of muscle fibers recruitment and of tonic reflex (16). During our experiment, we did not evaluate the sum and frequency of vibrations the pilots supported, and a role for this factor on EE elevation and fatigue development cannot be eliminated.

Finally, when questioned, pilots objectively mentioned fatigue development after each 45-minute driving relay and progressive fatigue accumulation all along the 24-hour race. This is in accordance with previous findings, which considered that speed driving is "a form of acute physical exercise that mobilizes the expression of diverse physiological functions" and that endurance driving "must prevail keeping up the whole system as long as the race lasts" (19). On the same way, it was suggested recently that peripheral fatigue could compromise endurance exercise performance by inhibiting central motor drive and result in an exaggerated HR response when compared with similar performance level (1). Because mean PAR and HR did not significantly vary during our experiment, we cannot point out any physical fatigue development in the pilots and concluded that even HR and PAR measurements remain a useful way to measure pilot adaptations to driving they are not sufficient alone to characterize fatigue components. Further investigations focusing on driving related tasks can be proposed. For example, handgrip forces measurements may allow evaluating actions on steerwheel. Postural responses can be managed to point out consequences of fatigue accumulation on limb or trunk muscles performances and processes of pain (discomfort) development during long-term driving. In both cases, EMG measurements also could be associated to reveal muscle fatigue and prevent risks of tissue damages.

Driving a kart during 45 -minute bouts at around $60 \mathrm{~km} \$ \mathrm{~h}^{21}$ resulted in a 300-kcal EET, corresponding to a 5.6-Mets PAR. This effort is responsive for $\mathrm{a}+73-\mathrm{b} \$ \mathrm{~min}^{21}$ increase in HR, reaching $82 / \mathrm{HR}_{\max }$ intensity $\left(157 \mathrm{~b} \$ \mathrm{~min}^{21}\right)$. These high values were repeatable between each successive bout but not sufficient to induce physiological fatigue. Thus, according to pilot statements, it can be proposed that psychoemotional fatigue could precede physiological muscular weakness and be responsive for early performance impairment.

\section{Practical Applications}

Fatigue is one of the main factors, with excessive speed and alcohol consumption, involved in road accident. In motor sports, when not taken into account, fatigue is known to compromise final performance by lowering anticipation movements, force exerted to control vehicle trajectory, and attention. Moreover, the lack of precise recommendations on maximal relay duration in relation to vehicle type exposes the pilot to fatigue development and crash events. Indeed, what is the ideal event duration for a F1 pilot, a kart pilot or a road driver? Are these durations similar? Few is known about it, but the development and the standardization of the use of small noncumbersome apparatuses to immediately follow pilot adaptation during simulated races or training sessions permanently increase our knowledge on bioenergetical needs and physiological stress induced. Conversely, a good knowledge 
on pilot adaptation and a strict follow-up of bioenergetical and physiological variables during race can allow to delay fatigue development and to optimize relay alternation during endurance events like 24-hour car races for example. As in other sports, such knowledge may allow for specific nutrition guidelines elaboration during effort period or during recovery period to prepare the next event.

As indicated previously, kart driving is a growing field of interest in leisure practices and is renowned to offer to nonexpert drivers similar speed sensations than to expert pilots. With this increased access to the activity, risk of trauma also increases. According to people protection rules and the pressure exerted by insurance companies, a better knowledge on relationships between specific motorsports needs, pilot capacities, and fatigue prevention could provide arguments for, in some case, limited access to kart or race car driving.

\section{ACKNOWLEDGMENTS}

The authors are grateful to the pilots and their staff, from the IUT of Chartres, France. They also want to thank Pr. J. Prioux and A. Le Faucheur (ENS Ker-Lann, Bruz, France) for the actimeter lending.

\section{REFERENCES}

1. Amann, M, Venturelli, M, Ives, SJ, McDuriel, J, Layer, G, Rossman, MJ, and Richardson, RS. Peripheral fatigue limits endurance exercise via a sensory feedback-mediated reduction in spinal motoneuronal output. J Appl Physiol 115: 355-364, 2013.

2. Backman, J, Häkkinen, K, Ylinen, J, and Kyrölaïnen, H. Neuromuscular performance characteristics of open-wheel and rally drivers. J Strength Cond Res 19: 777-784, 2005.

3. Baur, H, Müller, S, Hirschmüller, A, and Mayer, F. Reactivity, stability, and strength performance capacity in motor sports. $\mathrm{Br}$ Jsports Med 40: 906-910, 2006.

4. Beaune, B and Durand, S. Cardiac chronotropic adaptation to openwheel racecar driving in young pilots. Int J Perf Anal Sport 11: 325334, 2011.

5. Beaune, B, Durand, S, and Mariot, JP. Open-wheel race car driving. Energy cost for pilots. J Strength Cond Res 24: 2927-2932, 2010.

6. Burr, JF, Jamnik, VK, Shaw, JA, and Gledhill, N. Physiological demands of off-road vehicle riding. Med Sc Sports Exer 42: 1345-1354, 2010.
7. Carneiro Rodrigues, LO and De Castro Magalhaès, F. Car racing: In the heat of competition. Rev Bras Med Esporte 10: 216-219, 2004.

8. Eker, HH, Van Lieshout, EMM, Den Hartog, D, and Schipper, IB. Trauma mechanisms and injuries associated with go-karting. Open Orthopaedic J 4: 107-110, 2010.

9. El Aji, Y, Soudain-Pineau, M, Joly, P, and Bertucci, W. Effect of whole-body vibration frequency and amplitude in heart rate and fatigue perception. Comput Methods Biomech Biomed Engin 14:41-43, 2011.

10. Jacobs, PL, Olvey, SE, Johnson, BM, and Cohn, KA. Physiological responses to high-speed open-wheel racecar driving. Med Sc Sport Exer 34: 2085-2090, 2002

11. Konttinen, T, Kyrölaïnen, H, and Hâkkinen, K. Cardiorespiratory and neuromuscular responses to motocross riding. J Strength Cond Res 22: 202-209, 2008.

12. Matsumura, K, Yamakoshi, T, Yamakoshi, Y, Hirose, H, and Rolfe, $\mathrm{P}$. The effect of competition on heart rate during kart driving: A field study. BMC Res Notes 4: 342-347, 2011.

13. McKenna, F. The human factor in driving accident. An overview of approaches and problems. Ergonomics 25: 867-877, 2002.

14. Rachner, C, Platzer, HP, and Patterson, C. Physical characteristics of experienced and junior open-wheel car drivers. J Sports Sc 31: 58-65, 2013.

15. Schwaberger, G. Heart rate, metabolic and hormonal responses to maximal psycho-emotional and physical stress in motor car racing drivers. Int Arch Occup Environ Health 59: 579-604, 1987.

16. Sperlich, B, Kleinoeder, H, De Marée, M, Quarz, D, Linville, J, Haegele, M, and Mester, J. Physiological and perceptual responses of adding vibration to cycling. J Exerc Physiol Online 12: 40-46, 2009.

17. Taggart, $\mathrm{P}$ and Gibbons, $\mathrm{D}$. Motor car driving and the heart rate. $\mathrm{Br}$ Med J 1: 411-418, 1967.

18. Tanaka, H, Monahan, KD, and Seals, DR. Age-predicted maximal heart rate revisited. J Am Coll Cardiol 37: 153-156, 2001.

19. Tsopanakis, C and Tsopanakis, A. Stress hormonal factors, fatigue, and antioxidant responses to prolonged speed driving. Pharmacol Biochem Behav 60: 747-751, 1998.

20. Walker, SM, Dawson, B, and Ackland, TR. Performance enhancement in rally car drivers via heat acclimation and race stimulation. Comp Biochem Physiol_Part a 128: 701-707, 2001.

21. Watkins, ES. The physiology and pathology of formula one grand prix motor racing. Clin Neurosurg 53: 145-152, 2006.

22. Yamakoshi, T, Matsumura, K, Yamakoshi, Y, Hirose, H, and Rolfe, P. Physiological measurements and analyses in motor sports: A preliminary study in racing kart athletes. Eur J Sport Sc 10: 397-406, 2010. 